\section{Processed meat as carcinogen: Time for health warning labels?}

The International Agency for Research on Cancer (IARC), World Health Organization's (WHO) specialized cancer agency, has recently classified consumption of processed meat (e.g., hamburgers, sausages, nuggets, hotdogs, mortadella, bacon, salami, ham, and beef jerky) as "carcinogenic to human" (Group I) and read meat as "probably carcinogenic to humans" (Group 2A) after reviewing more than 800 epidemiological studies investigating association between consumption of red and/or processed meat and cancer [1]. The Working Group found "sufficient evidence" for colorectal cancer, $18 \%$ increased cancer risk with daily consumption of $50 \mathrm{~g}$ (less than the weight of one average size hotdog) of processed meat, and limited evidence for stomach cancer. Although, a metaanalysis [2], which pooled data from seven studies, has reported $19 \%$ increased risk of pancreatic cancer with daily consumption of $50 \mathrm{~g}$ of processed meat ( $R R=1.19$; 95\% CI 1.04-1.36), surprisingly, the Working Group included red meat only as a risk factor for pancreatic cancer.

This calls for an immediate action plan to increase general public's awareness about the hazards of consuming processed meat with an aim to reducing its consumption. Health warning labels, among many other methods (leaflets, seminars, workshops, media campaign) can be effective in increasing awareness. Effectiveness of health warning labels has been very well documented in literature $[3,4]$. Tobacco package health warning labels have been effective not only in increasing consumers' knowledge about the negative health consequences of tobacco use but also in changing consumer's attitudes and behavior toward tobacco use (e.g., smoking less, smoking less around others attempting to quit) [4]. Health warning labels should be considered for processed meat as both tobacco smoking and processed meat are Group 1 carcinogens and avoiding/limiting their consumption can reduce cancer risk. Health warning labels should not be imposed only on the manufacturers of processed meat but also on products prepared using processed meat including fast food as growing consumption of fast food particularly among children and teens is alarming. It has been estimated that over one in three children in US consume fast food daily with fast food, on average, contributing about $12 \%$ of their daily caloric requirements [5]. A strategic, multilevel health promotion and disease prevention campaign targeting children, parents, teachers, and school administrators is needed. Since health warning labels are cheap yet very effective in increasing awareness and modifying consumer's behavior, national and international public health authorities should pressurize governments to make necessary legislative changes, if required, to impose health warnings labels for food items containing processed meat. However, governments would need significant political will to sustain pressure posed by the processed meat manufacturers and giant fast food chains against the imposition of health warning labels.

\section{References}

[1] on behalf of the International Agency for Research on Cancer Monograph Working GroupV. Bouvard, D. Loomis, K.Z. Guyton, et al., Carcinogenicity of consumption of red and processed meat, Lancet Oncol. (2015), http://dx.doi. org/10.1016/S1470-2045(15)00444-1.

[2] S.C. Larsson, A. Wolk, Red and processed meat consumption and risk of pancreatic cancer: meta-analysis of prospective studies, Br. J. Cancer 106 (2012) 603-607

[3] D. Hammond, G.T. Fong, A. McNeill, et al., Effectiveness of cigarette warning labels in informing smokers about the risks of smoking: findings from the International Tobacco Control (ITC) Four Country Survey, Tob. Control 15 (2006) 19-25.

[4] Sambrook Research International, A Review of the Science Base to Support the Development of Health Warnings for Tobacco Packages, 2009, Available at http://ec.europa.eu/health/tobacco/docs/warnings_report_en.pdf (accessed 25.11.15).

[5] S. Vikraman, C.D. Fryar, C.L. Ogden, Caloric Intake from fast food among children and adolescents in the United States, 2011-2012. NCHS Data Brief, No. 213, 2015, Available at http://www.cdc.gov/nchs/data/databriefs/db213.pdf (accessed 25.11.15).

$$
\begin{array}{r}
\text { Muhammad Abdul Hadi a,b,* } \\
\text { a College of Pharmacy, Umm-Al-Qura University, } \\
13578 \text { Makkah, Saudi Arabia } \\
\text { b Pharmaceutical Research Centre, Deanship of } \\
\text { Scientific Research, Umm-Al-Qura University, } \\
\text { Makkah, Saudi Arabia }
\end{array}
$$

* Correspondence to: Department of Clinical Pharmacy, College of Pharmacy, Umm-Al-Qura University, Al-Abdia Campus, Makkah 13578, Saudi

Arabia.

E-mail addresses: abdulhadi83@gmail.com, mjbatish@uqu.edu.sa.

2 February 2016

6 March 2016

Available online 10 March 2016 